\title{
Favorecimento econômico e excelência escolar: um mito em questão
}

\author{
Maria Alice Nogueira \\ Universidade Federal de Minas Gerais, Faculdade de Educação
}

\section{Introdução}

A sociologia da educação - tanto no Brasil quanto no exterior - só muito recentemente passou a se interessar pela escolarização dos jovens pertencentes a famílias favorecidas do ponto de vista social, já que, tradicionalmente, é para os meios populares que a atenção do pesquisador se dirige. Atualmente a situação vem modificando-se com o surgimento de alguns trabalhos que deslocam o olhar da "desvantagem social para o privilégio" (Sirota, 2000, p. 166). Talvez, em nosso país, a prova mais bem acabada desse interesse seja a publicação, em 2002, da coletânea A escolarização das elites (Almeida \& Nogueira, 2002) que oferece um panorama da pesquisa nacional e internacional sobre o tema e que já se encontra em sua segunda edição.

No entanto, mesmo em terreno tão lacunar, uma distinção precisa ser feita. É que a reflexão sobre o impacto do patrimônio cultural familiar sobre a escolaridade dos filhos já se encontra bem mais desenvolvida, graças sobretudo aos estudos, de inspiração bourdieusiana, sobre a transmissão da herança cultu- ral pela família. Já o papel da riqueza econômica nos destinos escolares dos indivíduos não logrou ainda se constituir em objeto sistemático de pesquisa do sociólogo. A meu conhecimento, apenas duas exceções extemporâneas, diga-se de passagem - podem ser registradas: os trabalhos de Fourastié $(1970,1972)$ e o livro de Ballion (1977), ambos franceses.

Jean Fourastié, econometrista do Conservatoire National des Arts et Métiers (CNAM), em Paris, interrogou, ao longo de toda a década de 1960 e por meio de questionário, um conjunto de 1.276 famílias pertencentes a categorias socioprofissionais ditas "superiores": empresários da indústria, funcionários públicos de alto escalão, artistas célebres, médicos com alta reputação, egressos das grandes écoles francesas (Politécnica, Normal Superior e Central), englobando assim tanto as frações das elites bem aquinhoadas do ponto de vista cultural, quanto aquelas privilegiadas financeiramente. Seus resultados demonstraram que, embora essas categorias sociais apresentem taxas de sucesso escolar acima da média da população, elas não são imunes ao fracasso escolar, pois uma porcentagem considerável dos filhos dos pesquisados (30\%, 
em média) não teve acesso, na época, ao ensino superior. Entretanto, o autor constatou diferenças significativas entre os diferentes grupos ocupacionais investigados, as quais poderiam ser resumidas na conclusão maior da pesquisa, a saber: o desempenho escolar dos jovens oriundos das frações economicamente dominantes da amostra (os filhos de empresários), quando comparado ao das frações mais intelectualizadas (elites científicas e artísticas), se mostrou bem inferior.

Partindo dessas constatações de Fourastié, o sociólogo Robert Ballion debruçou-se sobre um tema absolutamente inusitado para os anos de 1970: o do insucesso escolar em meios altamente favorecidos do ponto de vista econômico. Mediante dados empíricos obtidos em universo de 670 alunos de estabelecimentos privados de ensino secundário, localizados em Paris e caracterizados por atender a uma clientela de filhos de homens de negócios, Ballion chegou a, pelo menos, duas conclusões de grande importância.

A primeira refere-se à constatação de que o índice de insucesso escolar, entre essas categorias sociais, é bem mais elevado do que se poderia supor, atingindo, por exemplo, quase a metade dos filhos de empresários da indústria. E a segunda diz respeito à descoberta, feita pelo autor, de que "l' argent efface l'échec" ou, em outros termos, de que as posses econômicas conseguem reparar, em boa parte, os prejuízos dos atrasos e dos acidentes ocorridos no percurso escolar. Isso porque essas famílias dispõem de meios de luta contra o insucesso escolar, através de estratégias variadas de compensação e de reparação, capazes de remediar ou, ao menos, de atenuar os efeitos nefastos do fracasso. Dentre essas estratégias, sobressaem aquelas relacionadas à escolha de certos tipos de estabelecimento de ensino, que o autor chamou de établissements de rattrapage, os quais funcionam como refúgio para alunos em situação de fracasso escolar, para os quais organizam uma estrutura especial de recepção.

Na pesquisa brasileira, ainda não contamos com estudos sobre $\mathrm{o}$ assunto, embora alguns trabalhos mais recentes, mas fora do campo da educação, tenham trazido alguma contribuição, ao se ocuparem das estra- tégias de reprodução próprias de determinados grupos sociais, dentre elas as que incidem sobre o uso da instituição escolar (Truzzi, 1991; Grün, 1992, 2002). Mas, de um modo geral, pode-se afirmar que o tema constitui território ainda a ser explorado entre nós.

Resolvi então aceitar o desafio de investigar em meios sociais favorecidos, colocando-me questões como: que tipo de trajetória escolar realizam os jovens provenientes de lares economicamente privilegiados? Quais são as condições sociais e familiares que tornam possíveis e inteligíveis esses destinos escolares? De que modo os privilégios ligados à família de origem podem constituir-se em trunfos (ou em obstáculos) perante os estudos?

Sem pretender nem poder responder a essas perguntas de modo cabal e completo no espaço deste trabalho, apresento aqui apenas alguns aspectos (e de forma bastante resumida) de uma pesquisa recentemente concluída, com a finalidade principal de abrir o debate.

Trata-se de um estudo realizado, em 2000-2001, com 25 famílias de grandes e médios(as) empresários(as) de Minas Gerais. ${ }^{1}$ Seu objetivo era conhecer as histórias escolares dos jovens e as estratégias educativas postas em prática por esses pais ao longo desses itinerários. Como instrumento de coleta dos dados, utilizei-me de entrevistas semidiretivas feitas com os próprios jovens e com suas mães, separadamente. O estudo baseia-se, portanto, num corpus formado por 50 entrevistas.

Sua origem imediata associa-se à minha perplexidade perante $o$ alto grau de disseminação, no senso comum, da ideologia de que o padrão de excelência escolar é apanágio dos "ricos" ou, em outros termos,

${ }^{1}$ Delimitei para estudo famílias em que o pai e/ou a mãe exercessem funções empresariais e, vivendo ou não em regime de união conjugal, tivessem filho(s) residente(s) no domicílio e em idade (esperada) de realização de estudos universitários. Porém, em razão de dificuldades encontradas no acesso a essa população, foi preciso incluir um caso de uma família cujo filho mais velho tinha, na época, 16 anos e cursava o ensino médio. 
de que as elites escolares se compõem de alunos "ricos". A tentativa é, portanto, a de colocar em questão algo que não é discutido usualmente, porque considerado (implicitamente) como indiscutível: o papel incondicionalmente positivo do capital econômico no destino escolar do aluno.

Por outro lado, sua origem teórica se enraíza numa problemática clássica na sociologia da educação: a dos fatores em jogo ou das mediações que se interpõem na relação entre o meio social de pertencimento e os resultados escolares, em particular a controvérsia sobre o peso relativo dos fatores culturais e dos fatores econômicos na definição dos rumos de uma trajetória escolar.

\section{As trajetórias escolares dos jovens pesquisados ${ }^{2}$}

O estudo das trajetórias escolares, lato sensu, não constitui propriamente uma novidade na sociologia da educação, pois, já a partir dos anos de 1960, os sociólogos passaram a se interessar pelas relações entre os percursos dos indivíduos no interior do sistema de ensino e seu meio social de pertencimento. No entanto, nesse primeiro momento, as interrogações recaíam sobre as macrorrelações entre o sistema escolar e a origem social, utilizando-se, geralmente, como metodologia de análise, o acompanhamento longitudinal (e em grande escala) de coortes de alunos, com o objetivo de observar a distribuição das oportunidades escolares. Consistindo basicamente numa análise de fluxos, esses estudos deixavam de considerar a dimensão individual das biografias escolares. ${ }^{3}$

Foi somente a partir da década de 1980 que se viu emergir um novo enfoque que se afasta duplamente da generalidade do modelo anterior. Primeiro, por-

${ }^{2}$ Em relação à variável sexo, o grupo de 25 jovens entrevistados compunha-se de 13 rapazes e 12 moças. Quanto à faixa etária, sua idade variou entre 16 e 26 anos.

${ }^{3}$ Exemplo clássico desse tipo de trabalho são as pesquisas realizadas nos anos de 1960/1970 pelo Institut National d'Études Démographiques (INED), na França. que desenvolve um interesse sociológico pela diversidade (relativa) dos destinos e das práticas escolares no interior de um mesmo meio social. Segundo, porque se interessa pelas histórias de vida escolar de indivíduos concretos ("de carne e osso") e pelos processos subjetivamente vividos e interpretados por eles. ${ }^{4}$

No período mais recente, a partir dos anos de 1990, surge uma nova abordagem inaugurada por pesquisadores que se interessam pelas trajetórias atípicas, excepcionais, inesperadas, em suma, aquelas que fogem às regularidades estatísticas que haviam sido descobertas nos anos de 1950/1960. Doravante, o "insignificante estatístico" vai tornar-se "sociologicamente significativo" (Baudelot, 1999). ${ }^{5}$

Assim, podemos afirmar sem receio a existência, nos dias atuais, de uma "sociologia das trajetórias escolares", embora tal afirmativa deva ser acompanhada da observação de que esta, a exemplo de toda a sociologia da educação contemporânea, abriga uma certa pluralidade interna: os horizontes teóricos, as formas de abordagem, os dispositivos metodológicos não são os mesmos de um autor a outro. Um ponto, no entanto, parece constituir consenso: o de que a trajetória escolar não é completamente determinada pelo pertencimento a uma classe social e, portanto, de que ela se encontra associada também a outros fatores, como as dinâmicas internas das famílias e as características "pessoais" dos sujeitos, ambas apresentando um certo grau de autonomia em relação ao meio social. ${ }^{6}$

Com relação à definição operacional do termo, a maioria dos pesquisadores concorda em considerar a

${ }^{4}$ Representam esse segundo momento trabalhos como os de Terrail (1984, 1990) sobre os operários, de Zéroulou (1988) sobre os imigrantes e de Berthelot (1993) sobre os camponeses.

${ }^{5}$ Constituem exemplos dessa última abordagem o artigo de Laacher (1990) e os livros de Laurens (1992), de Lahire (1997) e de Ferrand, Imbert e Marry (1999).

${ }^{6}$ No entanto, com relação à dimensão do "pessoal”, é preciso reconhecer, de acordo com Dubet (1996), que "a sociologia não dispõe [ainda] de categorias de análise sólidas” para enfrentá-la. 
trajetória como um "encadeamento temporal de posições sucessivamente ocupadas pelos indivíduos nos diferentes campos do espaço social" (Battagliola $e t$ al., 1991, p. 3), direcionando essa definição para o campo educacional. Em consonância com isso, um percurso biográfico escolar deverá ser captado por meio dos acontecimentos que o pontuam, com seus momentos decisivos, suas bifurcações e suas encruzilhadas.

No caso deste trabalho, optei por me apoiar essencialmente nas etapas institucionalizadas de um itinerário escolar (graus do ensino, processos seletivos), tal como se dá no sistema de ensino em vigor no país.

Um pouco mais da metade do grupo investigado sofreu alguma reprovação ao longo da escolaridade básica (ensino fundamental e médio). Mais precisamente, 13 jovens foram afetados, perfazendo juntos um total de 19 reprovações (cf. Tabela 1). Essas últimas, embora concentradas no segundo segmento do ensino fundamental e no ensino médio, não deixaram de atingir, em um quinto dos casos, alunos das primeiras quatro séries. Há que se acrescentar ainda a esses dados o fato de que quatro jovens passaram por cursos "supletivos": em três casos no nível do ensino médio, e no quarto, no nível do ensino fundamental ( $5^{\mathrm{a}}$ a $8^{\mathrm{a}}$ série) e médio. Esse último fenômeno concerne justamente àqueles alunos que tiveram, em seu percurso, duas ou mais reprovações.

Tabela 1 - Distribuição dos pesquisados segundo o desempenho escolar na educação básica

\begin{tabular}{|l|c|}
\hline \multicolumn{1}{|c|}{ Desempenho escolar } & № de pesquisados \\
\hline Nenhuma reprovação & 12 \\
\hline Uma ou mais reprovações & 13 \\
\hline Total & $\mathbf{2 5}$ \\
\hline
\end{tabular}

Os estudos sobre trajetórias constatam que, de um modo geral, as carreiras escolares vão construindose por etapas, e que é ao longo do tempo que o valor escolar de um indivíduo vai constituindo-se e adquirindo consistência, de forma a possibilitar - em determinados momentos - algum prognóstico quanto ao futuro do percurso dentro do sistema de ensino. No
Brasil, o vestibular representa o mais forte desses momentos, capaz de dar visibilidade ao caminho até então percorrido.

Menos da metade dos jovens atingiu a universidade em idade regular ou antes dela, isto é, aos 17 ou 18 anos. Como nesse meio social - diferentemente dos meios populares - o abandono/interrupção dos estudos, antes dessa idade, constitui fato raríssimo, isso significa que mais da metade do universo pesquisado apresentou algum tipo de atraso em seu itinerário escolar, decorrente seja das reprovações no nível do ensino fundamental ou médio, seja de tentativas malsucedidas no vestibular.

Tabela 2 - Distribuição dos pesquisados segundo a idade de entrada na universidade

\begin{tabular}{|c|c|}
\hline Idade de entrada & № de pesquisados \\
\hline $17-18$ & 10 \\
\hline $19-20$ & 11 \\
\hline $21-22$ & 1 \\
\hline $23-24$ & 1 \\
\hline Total & $\mathbf{2 3}$ \\
\hline
\end{tabular}

Obs.: O total 23 deve-se à ausência de dois sujeitos que não haviam ainda atingido o ensino superior no momento da entrevista.

Tabela 3 - Distribuição dos pesquisados segundo o número de tentativas de ingresso no ensino superior

\begin{tabular}{|l|c|}
\hline Número de tentativas & № de pesquisados \\
\hline Uma & 15 \\
\hline Duas & 6 \\
\hline Três & 2 \\
\hline Quatro & 1 \\
\hline Total & $\mathbf{2 4}$ \\
\hline
\end{tabular}

Obs.: O total 24 deve-se à ausência de um sujeito que não havia ainda concluído o ensino médio no momento da entrevista.

A defasagem acumulada no percurso não impedirá, no entanto, os jovens em atraso de ingressar no ensino superior, após um certo número de ensaios frustrados e mediante o auxílio largamente utilizado dos "cursinhos". Uma ampla maioria dos jovens serviuse deles (a metade por um período de um a dois anos; 
o restante por um período que ficou em torno de seis meses).

Além disso, há também o fato de que a escolha da instituição de ensino superior recai sobre instituições privadas que se caracterizam por praticarem exames vestibulares menos seletivos e, na maior parte, pouco exigentes. A tabela a seguir exibe o rol e a distribuição das instituições freqüentadas pelos jovens entrevistados:

Tabela 4 - Distribuição dos pesquisados por instituição de ensino superior freqüentada

\begin{tabular}{|l|c|}
\hline \multicolumn{1}{|c|}{ Instituição de ensino } & № de pesquisados \\
\hline PUC-MG & 9 \\
\hline FUMEC & 4 \\
\hline Newton Paiva & 2 \\
\hline UNA & 2 \\
\hline UNI-BH & 2 \\
\hline Izabela Hendrix & 1 \\
\hline IBMEC & 1 \\
\hline Promove & 1 \\
\hline UFMG & 1 \\
\hline Total & $\mathbf{2 3}$ \\
\hline
\end{tabular}

Obs.: O total 23 deve-se à ausência dos dois sujeitos que não haviam ainda atingido o ensino superior no momento da entrevista.

Uma distribuição bastante semelhante a essa foi verificada entre os irmãos dos interrogados que também se encontravam, no momento da coleta, cursando o ensino superior (36 casos), o que confere aos dados maior significado.

A esse respeito, um estudo recente e, possivelmente, o mais completo até hoje sobre o ensino superior privado no Brasil (Sampaio, 2000), desmente a suposição corrente - na opinião pública, na mídia e mesmo entre os gestores educacionais - de que os estudantes universitários da rede privada apresentam um nível socioeconômico mais baixo do que aqueles que estudam em instituições públicas de ensino superior. A autora mostra que as diferenças quanto ao pertencimento social entre esses dois grupos de estudantes são muito pequenas, indo, porém, no sentido inverso ao da crença comum, ou seja, o corpo discente dos estabelecimentos superiores particulares é li- geiramente mais elitizado do que aquele das instituições públicas (cf. Capítulo 6). Outro estudo ainda mais recente, realizado por Simon Schwartzman (2004) com base nos dados da Pesquisa Nacional por Amostra de Domicílios (PNAD/2001) e do Instituto Brasileiro de Geografia e Estatística (IBGE), questiona igualmente o senso comum de que a rede pública de ensino superior, no Brasil, abrigaria os estudantes mais ricos, enquanto os pobres só teriam acesso, nesse nível, ao ensino privado. $\mathrm{O}$ autor demonstra que o estudantado do ensino superior privado apresenta renda familiar superior à do estudantado da rede pública.

Tabela 5 - Distribuição dos irmãos dos pesquisados por instituição de ensino superior freqüentada

\begin{tabular}{|l|c|}
\hline \multicolumn{1}{|c|}{ Instituição de ensino } & № de pesquisados \\
\hline PUC-MG & 10 \\
\hline Milton Campos & 3 \\
\hline FEAD & 3 \\
\hline FUMEC & 3 \\
\hline UNI-BH & 3 \\
\hline Universidades no exterior & 3 \\
\hline UNA & 2 \\
\hline IBMEC & 2 \\
\hline UFMG & 2 \\
\hline Izabela Hendrix & 1 \\
\hline Newton Paiva & 1 \\
\hline Faculdades Machado Sobrinho & 1 \\
\hline FMU (São Paulo) & 1 \\
\hline UEMG (FUMA) & 1 \\
\hline Total & $\mathbf{3 6}$ \\
\hline
\end{tabular}

Com relação especificamente ao vestibular da UFMG, ${ }^{7}$ três quartos dos jovens tentaram (quase sempre, uma única vez), mas não obtiveram aprovação nesse vestibular. Quanto ao quarto restante, é razoável supor que, diante do alto grau de competitividade, jovens com preparo insuficiente, ou que assim se sintam, não se candidatem a esse exame vestibular

${ }^{7}$ A UFMG é uma das universidades públicas de maior prestígio do país e a mais conceituada do Estado de Minas Gerais, sendo seu vestibular altamente seletivo. 
por considerarem suas possibilidades de êxito como muito exíguas. Na verdade, dentre os 25 sujeitos focalizados pela pesquisa, apenas um cursava a UFMG, à qual teve acesso, no entanto, não pela via do vestibular, mas sim por meio de transferência a partir de uma faculdade privada do interior do estado. Todos os restantes freqüentavam, na época da pesquisa, estabelecimentos privados de ensino superior, como se viu na Tabela 4.

Tais resultados parecem questionar a idéia corrente de que para se conquistar uma vaga nas grandes universidades públicas de alto prestígio basta possuir recursos financeiros, os quais supostamente condicionariam um passado escolar de excelência que fatalmente levaria ao sucesso na seleção dessas instituições. É preciso também que os indivíduos estejam predispostos a ambicionar os destinos universitários mais favorecidos e a pôr em prática meios de conquistá-los.

Como no nível do ensino fundamental e médio esses jovens freqüentaram igualmente escolas particulares ${ }^{8}$ pode-se afirmar que a escolaridade dos filhos de empresários se desenrola, de ponta a ponta, na rede privada de ensino. Essa fidelidade ao ensino privado surpreende quando se trata de ensino superior, no qual a reputação e o prestígio das instituições públicas são, de um modo geral, bem superiores ao das particulares. Ela questiona, por um lado, as falsas evidências do senso comum que consistem em pensar que os "ricos" estudam em universidades públicas, enquanto os "pobres" o fazem nas instituições privadas de ensino superior. Mas, por outro, ela questiona também a extensão, a esse grupo social, da hipótese do "circuito virtuoso" que circula no meio aca-

${ }^{8}$ Não é meu propósito, neste texto, tratar da escolha dos estabelecimentos de ensino pelas famílias, embora esse tenha sido um ponto abarcado pela pesquisa. Esclareço apenas que, de um modo geral, a preferência dos pais não recai sobre os colégios particulares de maior reputação por suas exigências acadêmicas e por aparecerem habitualmente como "campeões" nos rankings de aprovação nos vestibulares mais concorridos. dêmico (cf. Souza, 1990-1991) e que prevê, para os favorecidos, em geral, freqüência a escolas privadas no nível da educação básica e, em seguida, ensino superior público.

Quanto ao ramo universitário escolhido, é nítida a orientação dominante para um certo tipo de formação superior: aquela que prepara para o mundo dos negócios e para a gestão empresarial, pois praticamente a metade dos jovens pesquisados optou pelo curso de Administração de empresas, como se vê na Tabela 6.

Tabela 6 - Distribuição dos pesquisados segundo o curso superior freqüentado

\begin{tabular}{|l|c|}
\hline \multicolumn{1}{|c|}{ Curso } & № de pesquisados \\
\hline Administração de empresas & 12 \\
\hline Arquitetura & 2 \\
\hline Relações públicas & 2 \\
\hline Publicidade e propaganda & 2 \\
\hline Psicologia & 2 \\
\hline Direito & 1 \\
\hline Medicina & 1 \\
\hline Pedagogia & 1 \\
\hline Total & $\mathbf{2 3}$ \\
\hline
\end{tabular}

Obs.: O total 23 deve-se à ausência dos dois sujeitos que não haviam ainda, no momento da entrevista, atingido o ensino superior.

Se a esse contingente acrescentarmos aqueles que fizeram opção por áreas conexas, como Publicidade e propaganda ou Relações públicas, teremos um agrupamento maciço dessa população em torno de um setor profissional específico: o da direção e organização do mundo da empresa. Os dois casos, na amostra, de jovens que não haviam ainda atingido o grau superior só vêm reforçar esse quadro: no primeiro deles, a formação secundária escolhida pelo jovem estava se dando em um curso denominado Técnico gerencial; e, no segundo, a jovem se preparava, no momento da entrevista, para prestar o vestibular para o curso de Administração de empresas.

Aumentando ainda mais o significado desses dados, a Tabela 7 mostra que entre os irmãos dos interrogados que, no momento da coleta, também se encontravam cursando o ensino superior a mesma tendência se verifica, apesar de maior dispersão das es- 
colhas. Se àqueles que cursam Administração de empresas juntarmos os irmãos que fizeram opção por áreas conexas (Economia, Publicidade e propaganda, Ciências contábeis, Comércio exterior, Design industrial, Marketing em design e Relações públicas), teremos mais da metade deles em ramos universitários ligados ao mundo empresarial.

Tabela 7 - Distribuição dos irmãos dos pesquisados segundo o curso superior freqüentado

\begin{tabular}{|l|c|}
\hline \multicolumn{1}{|c|}{ Curso } & № de pesquisados \\
\hline Administração de empresas & 10 \\
\hline Direito & 6 \\
\hline Engenharia civil & 4 \\
\hline Economia & 3 \\
\hline Arquitetura & 3 \\
\hline Publicidade e propaganda & 2 \\
\hline Ciências contábeis & 1 \\
\hline Pedagogia & 1 \\
\hline Comércio exterior & 1 \\
\hline Design industrial & 1 \\
\hline Decoração & 1 \\
\hline Marketing em design & 1 \\
\hline Relações públicas & 1 \\
\hline Matemática & 1 \\
\hline Total & $\mathbf{3 6}$ \\
\hline
\end{tabular}

A propensão aos estudos de Administração não distingue homens e mulheres pois os doze casos encontrados dividem-se em proporções praticamente iguais entre os sexos: sete rapazes e cinco moças (seis moças, quando se acrescenta o caso da então vestibulanda).

Qual o sentido subjetivo dessa escolha? O que dizem seus protagonistas? Ao justificar sua decisão por Administração, alguns jovens confessam tê-lo feito "por eliminação", na ausência de alternativas mais atraentes entre os ramos universitários existentes:

E como eu não gosto nem um pouco de Medicina, de Direito, nem muito de Exatas, eu fiquei meio em dúvida entre Engenharia e Administração. [...] Eu não tinha certeza absoluta, não. Mais por eliminação, de eu não querer mesmo outros cursos, então sobrou mais ou menos esses dois, eu preferi Administração que tem mais a ver com o negócio da família, uma coisa que me interessava. Eu via que meu pai gostava, e tal, então influenciou e eu fui fazer Administração.

Eu, pra falar a verdade, eu fiz Administração foi por falta de opção, porque eu não sei o que eu quero fazer.

Eu queria uma coisa mais ampla assim... nada ligada a Medicina, nada ligada a Engenharia, nada ligada a Humanidade, nada. Aí eu optei por Administração e nem fiz pesquisa, foi por exclusão.

François Dubet, em um estudo sobre o estudante universitário dos dias atuais, chama a atenção para esse fenômeno da "escolha negativa" que também encontrou entre seus interrogados. Ele recomenda que não se veja aí um sujeito sem projeto, mas sim alguém que só dispõe do projeto que pôde formular ao final de uma "série de renúncias". Para o autor, a concordância entre desejos e projetos é privilégio apenas de uma elite escolar, com real poder de escolha. Ele exemplifica com palavras altamente sugestivas: "Os estudos de Medicina não são nunca apresentados [pelos entrevistados] como uma escolha na falta de coisa melhor. Se é médico porque se escolheu ser médico 'desde sempre"” (Dubet, 1994, p. 520).

Nos casos em que justificativas para a opção pelo curso de Administração são fornecidas, os argumentos giram em torno de dois eixos. De um lado, são evocados aspectos objetivos, relacionados às características imputadas ao curso, em torno do qual paira um forte imaginário: o de ser um curso de fracas exigências acadêmicas.

Como eu nunca fui um cara de gostar de estudar em casa, de ler livros e ler essas coisas, eu falei... eu sempre que eu via meu irmão, o cara pra fazer Direito tem que estudar "igual a um cão", que ele tem que saber ler de trás pra frente e de frente pra trás, ler código disso, daquilo, código, código, código, e isso não é pra mim, e eu falei isso não é pra mim, Direito eu sabia que não era a minha praia, aí foi Administração. 
Mas também, e sobretudo, por ser um curso cujo conteúdo é de natureza muito geral, o que propiciaria uma certa maleabilidade, seja em termos de formação posterior, seja em termos de atividade profissional futura. Assim, o conteúdo do curso é visto mais em sua função instrumental de adaptação do que em sua dimensão de desenvolvimento intelectual:

Eu cheguei à conclusão que Administração é uma base de tudo. Aí, depois, é só fazer uma pós-graduação que você já... Por exemplo: eu faço Administração, e eu faço uma pós-graduação em Economia, eu acho que Administração seria o pilar da construção.

Eu acho que é um curso que os ensinamentos que estão lá são muito amplos, dá pra você usar em muitos campos, né? Eu acho que o curso de Administração te dá uma base de muitas coisas, entendeu? De Direito, de Contabilidade, de cada Administração específica, né? Logística... então, assim, é um campo muito amplo e eu acho que eu pensei Administração por isso.

Mas, por outro lado, os pesquisados - em sua maior parte - apontam razões do âmbito da individualidade (gosto, personalidade, vocação etc.) como responsáveis por sua opção com relação ao curso:

Eu queria uma coisa ligada à área de Matemática, eu adorava! Mas eu queria uma coisa mais geral, e foi Administração mesmo. Papai tinha uma factoring, aí eu fazia controle de cheque pra ele, juros, uns negócios...

Eu sempre gostei de Administração e Publicidade, mas também por ter a empresa, meu pai sempre me falou: "Você poderia optar, já que você tá entre as duas, você podia optar pela Administração".

O fato de eu ser filho de empresário e de eu não ter característica para fazer alguma outra coisa. De ver também que eu tenho característica para ser um administrador, pelo fato do meu jeito parecer um pouco com o do meu pai. Então, mais por isso, pela influência também.
Eu tava no terceiro ano [do ensino médio] e eu já tinha... eu queria Administração. Eu já sabia disso [...]. Acho que eu vi muito meu pai, assim... o que ele fazia, acabava que apesar de eu não entender muito assim aquela linguagem técnica que ele tava falando, eu assim... pequenininho, eu ia pra garagem, ${ }^{9}$ minha diversão era ficar brincando lá de almoxarifado, eu acho que entendia o que era aquilo, assim... uma visão diferente, mas entendia, aí eu acho que isso influenciou muito.

As falas anteriores sugerem que, no essencial, as preferências pessoais não se opõem aos constrangimentos exteriores que se manifestam, nesse caso, na forma da influência parental. O sentimento experimentado de realização de inclinações pessoais evidencia que o exercício da subjetividade pode se dar em harmonia com e no interior de imperativos de ordem social que escapam ao sujeito, sem que sua sensação de liberdade seja atingida. Qual é a alquimia que está por trás desse processo?

Uma das respostas sociológicas atualmente possíveis está na idéia de que as inclinações, preferências, disposições - aparentemente irredutíveis às estruturas sociais - não podem ser concebidas independentemente das condições de existência, em relação às quais representam "ajustamentos" que escapam, na maior parte do tempo, à consciência individual. $\mathrm{O}$ conhecimento desse processo subjetivo que leva o ator a amar seu destino social - o amor fati que propõe Bourdieu - afasta o risco de uma dupla armadilha, a saber: considerar as percepções e ações dos indivíduos seja como fruto de uma coerção social mecânica, seja como ato de pura liberdade.

Na verdade, um longo e lento processo de socialização familiar encarrega-se da constituição do gosto por alguma atividade (pelos negócios, por exemplo) e da transmissão de predisposições que possibilitam a integração a grupos sociais ou a universos profissio-

${ }_{9} \mathrm{O}$ pai é proprietário de uma empresa de transporte rodoviário. 
nais específicos. Nesse processo, a figura paterna desempenha papel fundamental, ainda segundo Bourdieu (1998, p. 232),

O pai é o sujeito e o instrumento de um "projeto" (ou, melhor, de um conatus) que, estando inscrito em suas disposições herdadas, é transmitido inconscientemente, em e por sua maneira de ser, e também, explicitamente, por ações educativas orientadas para a perpetuação da linhagem.

A surpreendente regularidade encontrada, nesta pesquisa, na conduta dos indivíduos no tocante à escolha do curso superior dificilmente pode ser pensada independentemente dos mecanismos que levam à reprodução das posições sociais mediante a propensão dos sujeitos a se orientarem no espaço social e a adotarem práticas (mesmo que de modo inconsciente) consoantes com seu pertencimento ou, dito em outros termos, da tendência dos agentes (indivíduos ou grupos) a "persistirem em seu ser social", a "perseverar no ser" (Bourdieu, 1980, 1998).

Mas, sabemos, nem todo filho de empresário torna-se fatalmente um empresário. Assim, estudos mais recentes defendem a tese de que é necessário que o "herdeiro aceite herdar a herança" (Bourdieu, 1998), ou seja, que ele aceite "apropriar-se" dela (Singly, 1996). Esse último ponto se refere à questão (que os sociólogos de hoje tentam enfrentar) da construção identitária dos sujeitos, que - nas sociedades contemporâneas, nas quais a individualidade é fortemente valorizada - podem vivenciar uma situação contraditória: ao mesmo tempo em que são levados a continuar a história familiar, devem se constituir em seres autônomos, por vezes ao preço da independência em relação à posição herdada, o que pode provocar conflitos existenciais e tensões internas.

\section{Conclusão}

As entrevistas com os jovens revelaram uma relação com a escola e com o saber predominantemente instrumental, no sentido de Charlot (2000), em que as finalidades perseguidas são, em sua maior parte, exteriores ao conhecimento em si mesmo e marcadas pelo utilitarismo, como, por exemplo, a obtenção da nota ou do diploma. Um relativo desapreço pelo universo escolar, ao qual corresponde um interesse quase apaixonado pelo mundo empresarial (o mundo das "coisas vivas") e pelos desafios que este lhes coloca, caracteriza esses estudantes.

Com efeito, do total de 25 filhos de empresários investigados, 17 conciliam estudos com o exercício de atividades profissionais e remuneradas. Dentre esses últimos, oito ingressaram no mundo do trabalho antes de atingir o ensino superior (um terço deles antes dos 18 anos) e nove a partir da entrada na universidade. Trata-se de uma verdadeira experiência do mundo dos negócios feita, na quase totalidade das vezes, nas empresas do pai ou da mãe; mas também, em alguns casos, em empresa própria, de pequeno porte, oferecida pelos pais, como por exemplo as "franquias". Em certos casos, o jovem começa pelos postos mais subalternos, como office-boy, por exemplo, e vai passando sucessivamente pelos vários setores da empresa, de acordo com o argumento de que isso é bom "para aprender" e conhecer o funcionamento global de um estabelecimento. São, em geral, situações de trabalho bastante formalizadas, o que significa ter a "carteira assinada" (algumas vezes como "estagiário"), com salários e horários definidos. ${ }^{10}$

Não se trata, evidentemente, de uma necessidade de auto-sustento ou de complementação do orçamento familiar, já que são jovens que recebem de suas famílias todo tipo de recursos materiais, incluindo certos consumos de luxo (viagens e carros caros, por exemplo). Segundo os filhos de empresários interrogados, as vantagens dessa inserção, desde cedo, no mundo empresarial são diversas. Entram aí a expectativa de "aprender a ganhar dinheiro"; a perspectiva de ocupar o tempo cotidiano que, para a grande maioria deles, os estudos sozinhos não conseguem preen-

\footnotetext{
${ }^{10}$ A quase metade dos entrevistados realizava seus estudos
} superiores no turno da noite, fenômeno usualmente associado, pela literatura sociológica, às camadas populares. 
cher; ${ }^{11}$ a necessidade de conhecer o mundo profissional "real", em contraposição à visão "abstrata" que a escola supostamente tem dele.

A percepção mais geral que fica para o pesquisador é a de que a escola é "pouco" para esses jovens, e isso em sentido múltiplo. É pouco porque toma apenas parte do tempo de sua rotina diária. São recorrentes, no discurso deles, expressões como: "meu tempo estava ocioso"; "eu ficava em casa sem fazer nada"; "à toa"; "sem ocupação", referindo-se aos períodos do dia em que não freqüentavam as aulas.

É pouco porque ocupa lugar secundário em suas preferências pessoais e afetivas: "por mim eu não estudava não, só trabalhava, mas...", declara uma das entrevistadas; "eu nunca gostei de estudar, eu não sei se eu gosto... mas eu gosto muito mais de trabalhar do que estudar", afirma um outro; "meu trabalho tá acima [dos estudos] e pronto!", sentencia um terceiro; ou ainda, nas palavras de mais um deles: "eu não gostava, eu não me sentia bem na aula, não gostava da faculdade, e até hoje eu não sinto o menor tesão da faculdade...".

A escola é pouco, ainda, porque desempenha papel secundário em sua preparação profissional, já que, a seu ver, transmite conhecimentos e teorias acadêmicas em grande descompasso com o dia-a-dia empresarial, não conseguindo portanto rivalizar com a realidade vivida no próprio meio. Um dos interrogados afirmou:

Tédio, me entedia profundamente [referindo-se aos estudos], principalmente depois de uma certa época que eu tava trabalhando com publicidade, desde 96, muita coisa que você vê na prática não bate com o que eles ensinam. Então você tem uma perda de tempo gigantesca, na minha

${ }^{11}$ Cabe lembrar que - como se viu - as escolhas dos ramos universitários, por parte desse grupo de jovens, não recaem sobre as carreiras mais exigentes do sistema de ensino, como os cursos superiores mais seletivos, em período integral. Tampouco eles realizam atividades acadêmicas extracurriculares, tais como: monitoria, iniciação científica, auxílio à pesquisa etc. visão. Eu acho que se fosse resumir o curso de Publicidade ou qualquer outro curso aí, não ia levar dois anos. Só que é tanta "encheção de lingüiça" e tanta "abobrinha", que leva quatro, cinco anos e no final é perda de tempo e dar dinheiro para os outros.

Essas concepções encontram eco nas representações e nos valores parentais verificados nas entrevistas com as mães, as quais revelaram, de um modo geral, a crença de que a formação para o empreendedorismo deve começar cedo e em família. A despeito das contradições e ambigüidades detectadas nos depoimentos maternos com relação à escolaridade dos filhos, essa inserção precoce no mundo dos negócios representa um poderoso fator de socialização, pois ela trabalha pela "formação de vocações" para o universo empresarial (Grün, 2002) ou, em outros termos, pela constituição do "gosto pelos negócios". Um desapreço pelo destino de "empregado", do qual tentam poupar os filhos, constitui a outra face desse discurso parental, assim como o ceticismo e a desconfiança em relação aos conhecimentos escolares, vistos como demasiadamente livrescos e abstratos.

Quanto às estratégias familiares, a melhor forma que encontro para caracterizar a relação que as famílias de empresários mantêm com o universo escolar é emprestada da linguagem ordinária: esses pais "não apostam todas as suas fichas na escola", investindo à semelhança dos filhos - moderadamente (sempre em termos relativos) no setor. Na verdade, os pais do meio empresarial se servem também (ou até mais) de outros tipos de estratégia para salvaguardar ou elevar a posição do grupo familiar no espaço social. Nesse sentido, pude detectar estratégias de tipo econômico, tais como: preparar os filhos desde muito cedo para sua sucessão; associá-los à empresa paterna; ou abrir para eles um pequeno negócio, ainda durante seu período de formação.

Quanto aos jovens, o fato de que eles não investem toda sua energia na causa escolar é, sem dúvida, o resultado de todo um processo de socialização familiar que escapa, em boa parte, à consciência dos sujeitos. O que não exclui atitudes de natureza mais 
racional e consciente: não tendo a sensação de que os estudos implicam uma via de mobilidade social ascendente, eles não vêem razão para se engajar escolarmente em troca de vantagens sociais tão pouco significativas. No entanto, em contradição com isso, percebem claramente a necessidade da caução escolar para legitimar a posição social economicamente dominante que serão chamados a ocupar. Assim, não deixam de ser sensíveis aos benefícios simbólicos do diploma: prestígio, respeitabilidade, legitimidade cultural, círculo de amizades, influências, alianças matrimoniais etc. Como seus pais, eles vivem, portanto, uma contradição interna entre, de um lado, a descrença no poder do diploma e, de outro, o reconhecimento de seu valor simbólico; contradição essa que não favorece a constituição de uma relação positiva e pessoal do jovem com a escola e não trabalha pela criação de um gosto pela escola ou pelo interesse por aquilo que lá é ensinado.

MARIA ALICE NOGUEIRA, doutora em educação pela Universidade de Paris V, é professora titular da Faculdade de Educação da UFMG e pesquisadora na área de sociologia da educação. Organizou recentemente duas coletâneas: Família e escola: trajetórias de escolarização em camadas médias e populares (com Geraldo Romanelli e Nadir Zago, Petrópolis: Vozes, 2000), na qual colaborou com o capítulo A construção da excelência escolar: um estudo feito com estudantes universitários provenientes das camadas médias intelectualizadas; e A escolarização das elites: um panorama internacional da pesquisa (com Ana Maria F. Almeida, Petrópolis: Vozes, 2002), na qual publicou o capítulo: Estratégias de escolarização em famílias de empresários. Participou também da coletânea L'enseignement supérieur au Brésil: enjeux et débats (Paris: IHEAL/COFECUB, 2002), com o capítulo La construction de l'excellence scolaire. Trajectoires et stratégies scolaires en milieu cultivé. Publicou ainda, em co-autoria com Cláudio Marques M. Nogueira, A sociologia da educação de Pierre Bourdieu (Educação \& Sociedade, nº 78, p. 15-36, abr. 2002). Atualmente coordena o projeto integrado de pesquisa: A construção da longevidade e da excelência escolar em famílias de diferentes meios sociais: processos e práticas de escolarização, no qual desenvolve o subprojeto: Cosmopolitismo científico e escolarização dos filhos: o caso das famílias de ex-bolsistas no exterior. E-mail: malicen@terra.com.br

\section{Referências bibliográficas}

ALMEIDA, Ana M.F., NOGUEIRA, Maria Alice (orgs.), (2002). A escolarização das elites: um panorama internacional da pesquisa. Petrópolis: Vozes.

BALLION, Robert, (1977). L'argent et l'école. Paris: Pernoud/ Stock.

BATTAGLIOLA, Françoise, BERTAUX-WIAUME, Isabelle, FERRAND, Michèle, IMBERT, Françoise, (1991). Dire sa vie. Paris: CSU/IRESCO/CNRS.

BAUDELOT, Christian, (1999). L'improbable est toujours possible. In: FERRAND, M., IMBERT, F., MARRY, C. L'excellence scolaire: une affaire de famille. Paris: L'Harmattan. Prefácio.

BERTHELOT, Jean-Michel, (1993). École, orientation, société. Paris: PUF.

BOURDIEU, Pierre, (1980). Le sens pratique. Paris: Minuit. , (1998). As contradições da herança. In: BOURDIEU, P. Escritos de educação. Petrópolis: Vozes, p. 229-237.

CHARLOT, Bernard, (2000). Da relação com o saber: elementos para uma teoria. Porto Alegre: Artmed.

DUBET, François, (1996). Avant-propos. In: SNYDERS, Georges. Y a-t-il une vie après l'école? Paris: ESF. Prefácio.

, (1994). Dimensions et figures de l'expérience étudiante dans l'université de masse. Revue Française de Sociologie, $\mathrm{n}^{\circ} \mathrm{XXXV}$, p. 511-532.

FERRAND, Michèle, IMBERT, Françoise, MARRY, Catherine, (1999). L'excellence scolaire: une affaire de famille. Paris: L'Harmattan.

FOURASTIÉ, Jean, (1972). Enquête sur la scolarité d'enfants appartenant à des milieux favorisés. Analyse et Prévision, $\mathrm{n}^{\mathrm{o}} 1-2$, juil.-août.

, (1970). Une enquête sur la scolarité d'enfants d'instituteurs et de normaliens. In: Institut National d'Études Démographiques (INED). Population et enseignement. Paris: PUF, p. 532-538.

GRÜN, Roberto, (2002). Dinheiro no bolso, carrão e loja no shopping: estratégias educacionais e estratégias de reprodução social em famílias de imigrantes armênios. In: ALMEIDA, 
A.M.F., NOGUEIRA, M.A. (orgs.). A escolarização das elites: um panorama internacional da pesquisa. Petrópolis: Vozes.

, (1992). Negócios \& famílias: armênios em São Paulo. São Paulo: Sumaré.

LAACHER, Smaïn, (1990). L'école et ses miracles? Note sur les déterminants sociaux des trajectoires scolaires des enfants de familles immigrées. Politix, no 12, p. 25-37.

LAHIRE, Bernard, (1997). Sucesso escolar nos meios populares: as razões do improvável. São Paulo: Ática.

LAURENS, Jean-Paul, (1992). 1 sur 500: la réussite scolaire en milieu populaire. Toulouse: Presses Universitaires du Mirail.

SAMPAIO, Helena, (2000). Ensino superior no Brasil: o setor privado. São Paulo: FAPESP/Hucitec.

SCHWARTZMAN, Simon, (2004). Equity, quality and relevance in higher education in Brazil. Anais da Academia Brasileira de Ciências, v. 76, $\mathrm{n}^{\circ}$ 1, p. 1-16.

SINGLY, François, (1996). L'appropriation de l'héritage culturel. Lien social et politique - RIAC, $\mathrm{n}^{\circ} 35$, printemps, p. 153-165.
SIROTA, Régine, (2000). Le métier d'élève. In: FORQUIN, J.C. (org.). Sociologie de l'education: nouvelles approaches, nouveaux objets. Paris: INRP.

SOUZA, Paulo R., (1990-1991). A universidade e a crise da educação. Revista da USP, no 8, p. 27-32, dez.-jan.-fev.

TERRAIL, Jean-Pierre, (1990). Destins ouvriers: la fin d'une classe? Paris: PUF.

, (1984). Familles ouvrières, école, destin social (1880-1980). Revue Française de Sociologie, v. XXV, nº 3, p. 421-436.

TRUZZI, Oswaldo, (1991). De mascates a doutores: sírios e libaneses em São Paulo. São Paulo: Sumaré/IDESP.

ZÉROULOU, Zaïhia, (1988). La réussite scolaire des enfants d'immigrés. Revue Française de Sociologie, v. XXIX, nº 3, p. $447-470$.

Recebido em outubro de 2003

Aprovado em janeiro de 2004 
time-space for the production of new knowledge. In this study, we analyse the processes of didactical/ museographical transposition and of recontextualization in spaces at science museums, in order to understand those mechanisms, which constitute the discourse expressed in expositions dealing with biological themes. Studies carried out in the educational and museological fields were used to understand the specificity, which museums impose on this process of production. In this paper, we give special attention to the construction of the theoretical framework used in the research process. The theoretical premises that were initially used were those of the concept of didacticall museographic transposition. Based on a critique of the limits of this concept, new theoretical principles were utilised taking as their principal support the concept of recontextualization. Finally, we seek to discuss the possibilities and limits of the use of the concept of didactical/museographic transposition and analyse the challenges of working with the concept of recontextualization in order to understand those educational processes, which take place in spaces offered by science museums.

Key-words: didactical transposition; recontextualization; museographic transposition; museum education

Alice Casimiro Lopes

Políticas curriculares: continuidade ou mudança de rumos?

Com base nas análises de Stephen Ball e nos conceitos de recontextualização (Basil Bernstein) e de hibridismo (García Canclini), analisa as políticas curriculares no Governo Lula. Defende que tais políticas ainda se desenvolvem sob influência da mesma comunidade epistêmica do Governo Fernando Henrique Cardoso e aponta os princi- pais marcos de mudança que poderiam ser desenvolvidos.

Palavras-chave: hibridismo; políticas de currículo; recontextualização

Curriculum policy: continuity or change?

Analyses the curriculum policies developed by the Lula Government. It concludes by stating that they belong to the same epistemological community as those developed by the previous

Fernando Henrique Cardoso

Government. It also mentions the main possible turning points, as far as Ball's analysis of curriculum policy,

Bernstein's recontextualization and Canclini's hybridism are concerned.

Key-words: curriculum policy; hybridism; recontextualization

\section{Mériti de Souza}

Fios e furos: a trama da subjetividade e a educação

Discute a constituição da subjetividade atravessada pelo pathos e pelo logos e remetida ao singular e ao coletivo.

Essa concepção demanda a análise do excluído da identidade individualizada do homem moderno e do conhecimento como ancorado exclusivamente na razão. Considerando o trabalho desenvolvido com a população escolar e a escuta dos discursos produzidos pela alocação dessas pessoas em lugares subjetivos perante o saber, indaga-se a possibilidade da prática pedagógica constituir-se em experiência produzindo efeitos de subjetivação.

Palavras-chave: subjetividade; educação; escola; modernidade

Threads and holes: the plot of subjectivity and education

Discusses the constitution of subjectivity cut through with pathos and logos and addressed to the singular and the collective. This conception requires the analysis of that which is excluded from the individualised identity of modern man and of knowledge as anchored exclusively in reason. Based on research developed with the school population and on listening to speeches produced by these people situated in subjective places with relation to knowledge, we question the possibility of pedagogical practice constituting experience, which produces subjective effects.

Key-words: subjectivity; education; school; modernity

Maria Alice Nogueira

Favorecimento econômico e excelência escolar: um mito em questão

Na pesquisa educacional brasileira ainda carecemos de estudos sobre os processos de escolarização dos jovens originários de famílias privilegiadas do ponto de vista econômico. O presente trabalho propõe-se a incursionar, portanto, em terreno altamente lacunar, apresentando alguns resultados parciais de um estudo realizado, em 2000-2001, com 25 famílias de grandes e médios empresários(as) de Minas Gerais, cujo objetivo principal era conhecer as histórias escolares dos jovens e as estratégias educativas postas em prática por esses pais ao longo desses itinerários. Um corpus de 50 entrevistas, feitas com os jovens e suas mães, foi reunido. Suas conclusões permitem questionar a idéia corrente de que o padrão de excelência escolar é apanágio dos "ricos" ou, em outros termos, de que as elites escolares se compõem de alunos "ricos".

Palavras-chave: trajetórias escolares; estratégias educativas familiares; relação família-escola

\section{Economic privilege and school excellence}

In Brazilian educational research we still lack studies which focus on the schooling process of youngsters from families privileged from the economic point of view. This paper aims, therefore, 
to make an incursion into a highly incomplete field, presenting some partial results of a study undertaken in 2000-2001, with 25 families of average to successful entrepreneurs from Minas Gerais. The aim of the study was to learn about the young people's school history and the educational strategies used by their parents during that time. A corpus of 50 interviews conducted with the youngsters and their mothers was compiled. Our conclusions allow us to question the current belief that the pattern of school excellence is a privilege of "the rich", or in other terms, that school élites are composed of "rich" students.

Key-words: school trajectory; family educational strategies; school/family relations

Ângela C. de Siqueira

\section{A regulamentação do enfoque comercial no setor educacional via OMC/GATS}

Aponta o crescente interesse de grupos empresariais na área educacional, perante o grande volume de recursos nela envolvidos, apresentando a perspectiva de inclusão da educação, como serviço, na agenda do Acordo Geral Sobre Comércio em Serviços, regido pela ótica da Organização Mundial do Comércio. Para tanto, analisa documentos da OMC, do GATS, propostas apresentadas por alguns países, evidenciando o interesse destes na eliminação de "barreiras" para seu "livre comércio". Sinaliza que a existência de regulamentações nacionais e mesmo a oferta do ensino público podem ser questionados como práticas prejudiciais à livre oferta de serviços educacionais, sujeitos às sanções da OMC, entre as quais os grupos empresariais poderão vir a exigir recebimento de recursos públicos e outros benefícios. Alerta para o fato de que, caso o GATS se concretize, correse o risco da transformação da educa- ção de direito público subjetivo em simples comercialização de pacotes educacionais (cursos, sistemas de avaliação e certificação, livros, uniformes, mapas etc.). Conclui, indicando que tal perspectiva fere a soberania e autonomia das nações, em um caminho que pode levar à perda da diversidade cultural e de valores locais, em benefício de um processo de homogeneização cultural, o que vem sendo contestado com a emergência de movimentos contrários.

Palavras-chave: comercialização da educação; privatização; Organização Mundial do Comércio; Acordo Geral sobre Comércio em Serviços

The regulation of the commercial approach to the educational sector by WTO/ GATS

The text indicates the entrepreneurial groups'growing interest in the educational field given the large amount of resources involved, presenting the perspective of including education, as a service, on the agenda of the General Agreement on Trade in Services, as a World Trade Organisation directive. To this end, it analyses WTO and GATS documents, as well as proposals presented by some countries, demonstrating their interests in eliminating "barriers" to "free trade" in education. The text points out that the existence of national regulations and even the offer of public education can be challenged as practices which are harmful to the "free" offer of educational services and subject to WTO sanctions allowing business groups to demand public resources and other benefits. Should GATS succeed, it runs the risk of converting education from a subjective public right into a process of simple commercialisation of educational packages (e.g. courses, systems of evaluation and certification, textbooks, uniforms, maps etc.). It concludes by indicating that such a perspective clearly endangers national sovereignty and autonomy, leading potentially to the loss of cultural diversity and local values, to the benefit of a process of cultural homogeneity. Notwithstanding, it also highlights the emergence of movements opposing this tendency. Key-words: commercialisation of education; privatisation; World Trade Organisation; General Agreement on Trade in Services

Munir Fasheh

Como erradicar o analfabetismo sem erradicar os analfabetos?

O texto desafia várias suposições que estão freqüentemente embutidas nas discussões oficiais sobre alfabetização, questionando o valor inerentemente libertador e positivo do processo de alfabetização, com base na necessidade de respeitar e revalorizar a diversidade de formas de aprender, estudar, conhecer e se expressar. Argumenta que liberação e liberdade estão articuladas à diversidade e ao pluralismo e que a educação representa apenas uma das formas de aprender. Afirma que o universalismo, mais do que qualquer outra coisa, tem sido a causa principal para se eliminar a diversidade considerada a essência da vida. Sugere que a adoção da alfabetização como forma dominante de conhecimento pode contribuir para o desaparecimento da diversidade e para a predominância de um único caminho para o progresso e o desenvolvimento. Palavras-chave: analfabeto; alfabetização; linguagem; conhecimento; diversidade

How to erradicate illiteracy without erradicating illiterates?

The text challenges various suppositions which are frequently included in official discussions on literacy, questioning the inherent liberating and positive value of the literacy process on the basis of the 